\title{
Controlled delivery of membrane proteins to artificial lipid bilayers by nystatin-ergosterol modulated vesicle fusion
}

\author{
M.R.R. de Planque, G.P. Mendes, M. Zagnoni, M.E. Sandison, K.H. Fisher, R.M. Berry, A. Watts and H. Morgan
}

\begin{abstract}
The study of ion channels and other membrane proteins and their potential use as biosensors and drug screening targets require their reconstitution in an artificial membrane. These applications would greatly benefit from microfabricated devices in which stable artificial lipid bilayers can be rapidly and reliably formed. However, the amount of protein delivered to the bilayer must be carefully controlled. A vesicle fusion technique is investigated where composite ion channels of the polyene antibiotic nystatin and the sterol ergosterol are employed to render proteincarrying vesicles fusogenic. After fusion with an ergosterol-free artificial bilayer, the nystatinergosterol channels do not dissociate immediately and thus cause a transient current signal that marks the vesicle fusion event. Experimental pitfalls of this method were identified, the influence of the nystatin and ergosterol concentration on the fusion rate and the shape of the fusion event marker was explored, and the number of different lipid species was reduced. Under these conditions, the $\beta$-amyloid peptide could be delivered in a controlled manner to a standard planar bilayer. Additionally, electrical recordings were obtained of vesicles fusing with a planar lipid bilayer in a microfabricated device, demonstrating the suitability of nystatin-ergosterol modulated vesicle fusion for protein delivery within microsystems.
\end{abstract}

\section{Introduction}

Membrane proteins account for an estimated $20-30 \%$ of the human proteome, and many of these ion channels, receptors and transport proteins play a paramount role in (patho)physiological processes, as evident from the high percentage $(\sim 60 \%)$ of pharmacological drugs that have a membrane protein target [1-4]. Because they traverse the hydrophobic interior of cell membranes, integral membrane proteins inherently have hydrophobic surface areas and this greatly complicates their characterisation outside a membrane environment, which is reflected in the fact that less than $1 \%$ of proteins with a known three dimensional structure are membrane proteins [5]. For functional studies, however, a membrane protein can (and should) be present in a membrane, either in its native biomembrane environment, as part of a multitude of different protein and lipid components, or purified and reconstituted in a model membrane consisting of a lipid bilayer of selected synthetic lipids [6].

(C) The Institution of Engineering and Technology 2006

IEE Proceedings online no. 20050039

doi:10.1049/ip-nbt:20050039

Paper first received 21st October 2005 and in final revised form 13th January 2006

M.R.R. de Planque, G.P. Mendes, K.H. Fisher and R.M. Berry are with the Bionanotechnology IRC, Clarendon Laboratory, Department of Physics, University of Oxford, Parks Road, Oxford OX1 3PU, UK

M.R.R. de Planque, G.P. Mendes, K.H. Fisher and A. Watts are with the Biomembrane Structure Unit, Department of Biochemistry, University of Oxford, South Parks Road, Oxford OX1 3QU, UK

M. Zagnoni, M.E. Sandison and H. Morgan are with the School of Electronics \& Computing Science, University of Southampton, Southampton SO17 1BJ, UK

E-mail: m.deplanquel@physics.ox.ac.uk
The electrical conductance of ion channel proteins has been studied in biomembrane vesicles and in artificial planar lipid bilayers by single-channel electrical recordings for decades [7, 8], yielding valuable information about the ion selectivity and gating mechanisms of many channels at a single-molecule level. With the much more recent advances in single-molecule spectroscopy $[9,10]$, it is becoming feasible simultaneously to perform electrical and optical measurements on single channels, which could provide insight into the dynamic aspects of ion channel function, such as subunit assembly, the interaction with regulators of channel activity, and the conformational transitions associated with channel gating [11, 12]. Very recently, such combined optical and electrical recordings have been reported for fluorescently labelled analogues of the small peptide ion channel gramicidin $[13,14]$ and a potassium channel [15].

However, the methods demonstrated to date for simultaneous optical and electrical recordings of ion channel activity in bilayers are not amenable to integration in an automated microfluidic system. Central to the design of a suitable technology platform for combined measurements is a microfabricated device, within which the lipid bilayer is formed. In recent years, several methods for making such devices have been reported in the literature [16]. These devices have been centred around an aperture that is formed in a hydrophobic material, such as a polymer film or silanised silicon, so that an artificial planar lipid bilayer can be formed [17-19]. Furthermore, microfabricated systems can incorporate many individually addressable membrane sites, allowing for parallel measurements. We have previously developed devices based on both micromachined silicon [20] and polymer embossing technologies [21]. The former, however, are very limited in their application, owing to fabrication difficulties and to parasitic capacitance 
problems that place severe limits on the electrical bandwidth.

Microsystems are attractive for many reasons, but obvious applications are in the field of high-throughput drug screening and biosensor applications [22, 23]. In order for such systems to operate efficiently and reliably, a controllable method for the delivery of proteins to the planar bilayer is required. Unlike membrane peptides, membrane proteins cannot be premixed with the lipid components in organic solvent. Some peripheral and integral membrane proteins are able to associate with or insert into a lipid bilayer directly from aqueous solution, but these are rare cases and do not include the pharmacologically relevant receptor proteins $[3,4]$. Moreover, any molecule in solution will have to be present in a sufficiently high concentration to enable bilayer contact within a reasonable time period, but, in this scenario, incorporation of only a small amount of material, an absolute requirement for single-molecule studies, is difficult to achieve.

Instead, fusion of small protein-containing vesicles with the planar bilayer offers significant advantages as a delivery method: in a typical membrane protein purification protocol, detergent removal coincides with vesicle incorporation [24], the amount of protein in the vesicles is under control, and, as vesicle fusion needs to be induced $[25,26]$, it can also be prevented once enough fusion has occurred. In the absence of charged lipids, vesicle fusion is driven exclusively by osmosis. This only requires an osmotic gradient over the planar bilayer (established by using different salt concentrations) and vesicles that are permeable to solute, as is the case when they contain open channels $[25,26]$.

To create permeable vesicles, Woodbury and Miller used channels that were formed from the polyene macrolide nystatin [27, 28], an antibiotic secreted by Streptomyces noursei (Fig. 1). Barrel-like oligomers of polyene macrolides, such as nystatin and amphotericin B, form weakly anionselective channels in the presence of membrane sterols [32-36], with the largest conductances obtained in the presence of ergosterol [37-40]. Woodbury and Miller exploited the dependence of nystatin channel activity on the presence of a membrane sterol by incorporating the membrane protein of interest into ergosterol-rich vesicles containing nystatin, while using an ergosterol-free planar lipid bilayer. Hence, the nystatin-ergosterol channels in the vesicles enable vesicle fusion but, following the fusion event, the nystatin-ergosterol channel activity gradually disappears as the ergosterol diffuses away into the ergosterol-free lipid bilayer, while the ion channel activity of the introduced protein remains (as shown schematically in Fig. 2) [27, 28]. Thus the nystatin-ergosterol channels not only render the protein-delivering vesicles fusogenic, but also clearly mark each fusion event as a transient ion current spike. This easy detection of individual fusion events is a significant advantage for developing vesicle delivery systems for planar bilayers on microfabricated devices.

In the present study, experimental pitfalls of the nystatinergosterol vesicle fusion method were identified, and several parameters of the method were varied using a standard planar bilayer workstation. The influence of the nystatin and ergosterol concentration on the fusion rate and the conductance of the fusion event marker was explored, and the lipid composition of the planar bilayer and the vesicles was simplified. Optimised conditions were established to enable us to incorporate the $\beta$-amyloid peptide, which has been implicated in Alzheimer's disease [41], in a controlled and reliable manner into a standard planar bilayer, and also
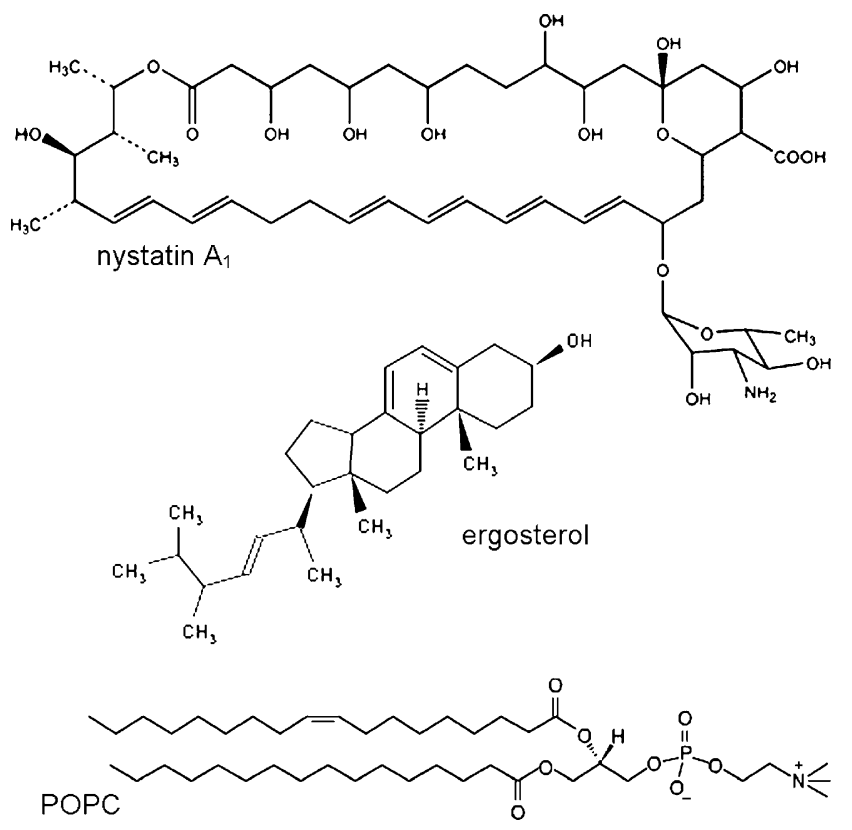

Fig. 1 Molecular components of the nystatin-ergosterol vesicle fusion method

Nystatin is a mixture of structurally similar polyene macrolide antibiotics secreted by Streptomyces noursei, of which nystatin $A_{1}$ is the main component [29]. An estimated eight nystatin molecules form a barrel-stave type pore in which the polyhydroxy moieties line the aqueous channel, and the tetraene groups are in contact with the lipid acyl chains of the membrane. The nystatin-nystatin interaction is stabilised by sterol molecules, with ergosterol being more effective than cholesterol. Because ergosterol is abundant in fungal cell membranes, nystatin and related polyene macrolides such as amphotericin B are widely used as fungicidal agents [30]. Note that the effective length of the acyl chains in bilayers of phospholipids such as 1-palmitoyl-2oleoyl-sn-glycero-3-phosphatidylcholine (POPC) is reduced because of chain disordering, whereas the macrolide ring of nystatin is relatively rigid, enabling a single polyene macrolide molecule to span a (relatively thin) POPC bilayer $[31,36]$

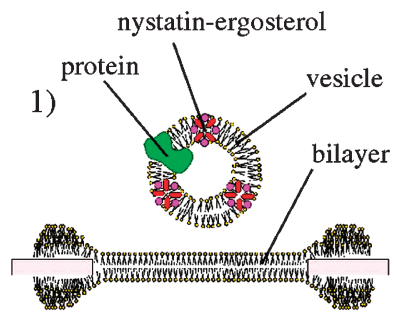

2)
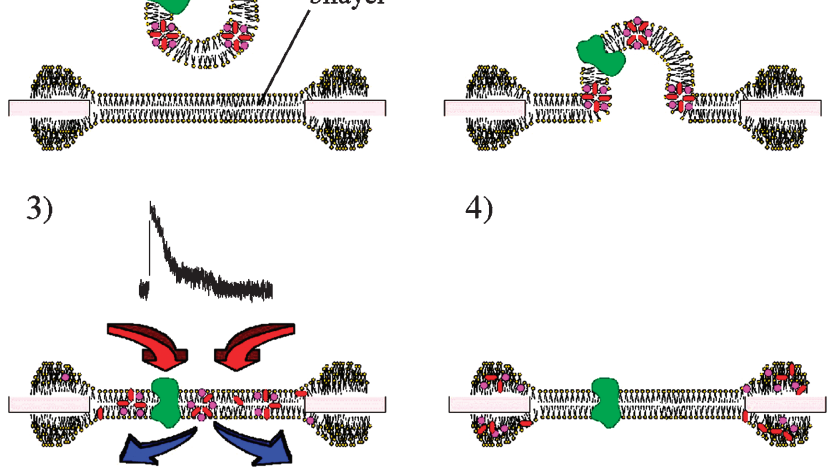

4)

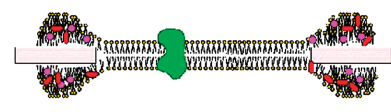

Fig. 2 Schematic diagram of the nystatin-ergosterol vesicle fusion method

Vesicles containing nystatin, ergosterol and the membrane protein of interest are added to the solution surrounding a lipid bilayer (1). The nystatin and ergosterol associate to form multimeric channels that facilitate fusion of the vesicles with the bilayer (2), with each fusion event being marked by a rapid increase in the recorded current, owing to ionic conduction through the nystatin-ergosterol channels. However, the current due to these channels gradually decreases to the baseline, as the ergosterol diffuses away into the ergosterol-free bilayer (3), thereby causing the nystatin-ergosterol channels to dissociate, while the membrane protein of interest remains active (4) 
to record electrically vesicle fusion on a microfabricated device.

\section{Materials and methods}

\subsection{Materials}

The synthetic phospholipids 1-palmitoyl-2-oleoyl-snglycero-3-phosphatidylcholine (POPC), 1-palmitoyl-2-oleoylsn-glycero-3-phosphatidylethanolamine (POPE) and 1-palmitoyl-2-oleoyl-sn-glycero-3-phosphatidylserine (POPS) were purchased from Avanti Polar Lipids (Alabaster, AL). Anhydrous methanol (99.8\%), chloroform (99.9\%), decane ( $\geq 99 \%$ ), trifluoroacetic acid (TFA, $\geq 99 \%$ ) and trifluoroethanol (TFE, $\geq 99 \%$ ) were obtained from Aldrich (St. Louis, MO). Ergosterol ( $\geq 75 \%$ ) was obtained from Sigma (St. Louis, MO). Nystatin dihydrate, as a mixture of different nystatin species, was obtained from Sigma, ICN Biomedicals (Aurora, OH) and Fluka (Buchs, Switzerland), and nystatin $\mathrm{A}_{1}$ trihydrate was obtained from Riedel-de Haën (Seelze, Germany). $\beta$-amyloid (1-40) peptide was provided by Dr Dirk T.S. Rijkers (Department of Medicinal Chemistry, Utrecht University, The Netherlands).

\subsection{Nystatin solubilisation}

Nystatin is poorly soluble $\left(4 \mathrm{mg} \mathrm{ml}^{-1}\right.$ in water and $11.2 \mathrm{mg} \mathrm{ml}^{-1}$ in methanol at $28{ }^{\circ} \mathrm{C}$ [42]) and chemically unstable; solutions and aqueous suspensions begin to lose antifungal activity soon after preparation [43]. In our experience, reproducible vesicle fusion can only be obtained when the starting material is a fine powder with a pale yellow colour. This indicates that the material is relatively anhydrous, a requirement for solubilisation in methanol. When nystatin is supplied as a light brown material with a somewhat sticky consistency, lyophilisation (after initial suspension in anhydrous methanol and bath sonication) is necessary to remove adsorbed atmospheric water, but this treatment is not always effective. In recent experiments, we used either lyophilised nystatin dihydrate from Fluka or nystatin $\mathrm{A}_{1}$ trihydrate as supplied. Only fresh stock solutions in anhydrous methanol were used for sample preparation, and exposure of the nystatin solution and samples to light was minimised. Also stock solutions of ergosterol (recrystallised twice from ethanol) in chloroform need to be protected from light, although these can be stored for months at $-20^{\circ} \mathrm{C}$.

\subsection{Unilamellar vesicle preparation}

Aliquots of stock solutions $(\sim 25 \mathrm{mM})$ of POPC, POPE and POPS in methanol/chloroform $(1 / 1, \mathrm{v} / \mathrm{v})$ and of ergosterol in chloroform were mixed in the desired molar ratio, the organic solvents were evaporated under a stream of nitrogen, and the resulting lipid film (containing $7.5 \mu \mathrm{mol}$ total lipid) was dried overnight under high vacuum to remove residual solvent traces. This film was hydrated with $1 \mathrm{ml}$ of high-salt buffer [10 mM HEPES, pH 7.4, $720 \mathrm{mM}$ $\mathrm{NaCl}$, and the resulting suspension of multilamellar vesicles was subjected to between 5 and 10 freeze-thaw cycles to improve the size homogeneity of the multilamellar vesicles. Using a mini-extruder (Avanti Polar Lipids), the vesicle suspension was passed 21 times through a polycarbonate filter with a pore size of $400 \mathrm{~nm}$ (Whatman; Clifton, NJ), resulting in a suspension of unilamellar vesicles of the same diameter. Subsequently, typically $10 \mu$ of a freshly prepared, bath sonicated $\left(\sim 10 \mathrm{~min}, 20^{\circ} \mathrm{C}, 350 \mathrm{~W}\right.$ power, 2.751 bath volume), clear solution of nystatin in anhydrous methanol $\left(1 \mathrm{mg} \mathrm{ml}^{-1}\right)$ was added to $200 \mu \mathrm{l}$ of the vesicle suspension, resulting in a nystatin concentration of $50 \mu \mathrm{g} \mathrm{ml}^{-1}(54 \mu \mathrm{M})$.
The nystatin-containing vesicle samples were incubated at room temperature, with occasional vortexing, to allow time for the nystatin molecules to associate with the vesicles [39]. For samples with the $\beta$-amyloid (A $\beta$ ) peptide, $0.15 \mu \mathrm{mol}$ of A $\beta$ was predissolved in TFA [44], the excess of TFA was removed with a nitrogen flow, and the $A \beta$-TFA film was redissolved in TFE. This solution was added to a lipid mixture in organic solvent and dried, resulting in a mixed film with a peptide to lipid molar ratio of $1: 200$, which was then treated in the same way as a peptide-free lipid film.

\subsection{Electrical bilayer recordings in conventional systems}

Planar lipid bilayers were formed across a $150 \mu \mathrm{m}$ aperture in the wall of a Delrin cup with a working volume of $1 \mathrm{ml}$ (Warner Instruments; Hamden, CT). A small amount of a POPE-POPC (7:3 molar ratio) solution in decane $\left(20 \mathrm{mg} \mathrm{ml}^{-1}\right)$ was applied to the area around the aperture and was allowed to air dry. The cup was placed in a bilayer chamber (Warner Instruments), the cis and trans chambers were both filled with $1 \mathrm{ml}$ of low-salt buffer $[10 \mathrm{mM}$ HEPES, pH 7.4, $150 \mathrm{mM} \mathrm{NaCl}$, and a planar lipid bilayer was painted by depositing a small drop of the lipidcontaining decane solution on the aperture. Formation and thinning of the bilayer were monitored by capacitance measurements; final capacitance values ranged from 70 to $100 \mathrm{pF}$, corresponding to bilayers of specific capacitance of approximately $0.5 \mu \mathrm{F} \mathrm{cm}^{-2}$. Subsequently, a $100 \mu 1$ aliquot was removed from the cis chamber and replaced with $100 \mu \mathrm{l}$ of a $3 \mathrm{M} \mathrm{NaCl}$ solution in distilled water, and the chamber contents were carefully mixed. This procedure was repeated once with $100 \mu \mathrm{l}$ and once with $50 \mu \mathrm{l}$ of $3 \mathrm{M} \mathrm{NaCl}$, giving a final cis chamber $\mathrm{NaCl}$ concentration of $720 \mathrm{mM}$. The cistrans salt gradient facilitates vesicle fusion $[45,46]$. Between 2 and $10 \mu \mathrm{l}$ of vortexed vesicle suspension was added to the cis chamber, near the aperture. A membrane holding potential of $65-100 \mathrm{mV}$ was applied, with $\mathrm{Ag} / \mathrm{AgCl}$ electrodes positioned directly in the cis and trans (virtual ground) chambers, and the current signal, filtered at $1 \mathrm{kHz}$, was measured using a bilayer membrane admittance meter (model ID 562, Industrial Development Bangor; Gwynedd, UK). The signal was digitised with a BNC-2110 adapter and connected to a personal computer with a PCI-6014 data acquisition board (National Instruments; Austin, TX). Current data points were recorded at a rate of either 250 or $2500 \mathrm{~Hz}$ with LabView software (National Instruments), and single-channel conductance events were analysed using pClamp 9 software from Axon Instruments (Foster City, CA).

\subsection{Electrical bilayer recordings on-chip}

Although traditional silicon fabrication methods are well developed and offer the potential for high-resolution devices, these methods are often costly and time-consuming. Therefore rapid manufacturing techniques, such as hot embossing, injection moulding and soft lithography, are increasingly being employed for the production of microfluidic systems [47]. These techniques focus on the manufacturing of low-cost polymeric devices with a rapid turnaround time. The use of hot-embossing was explored for fabricating a microfluidic channel to obtain the cis reservoir [20], and an aperture $(100 \mu \mathrm{m}$ diameter, $<120 \mu \mathrm{m}$ thickness) was created in the centre of this channel by laser micromachining. A poly(methylmethacrylate) (PMMA) well was placed over the aperture to act as the cis reservoir, and the base of the channel was sealed using a glass coverslip (as illustrated in Fig. 3a). 


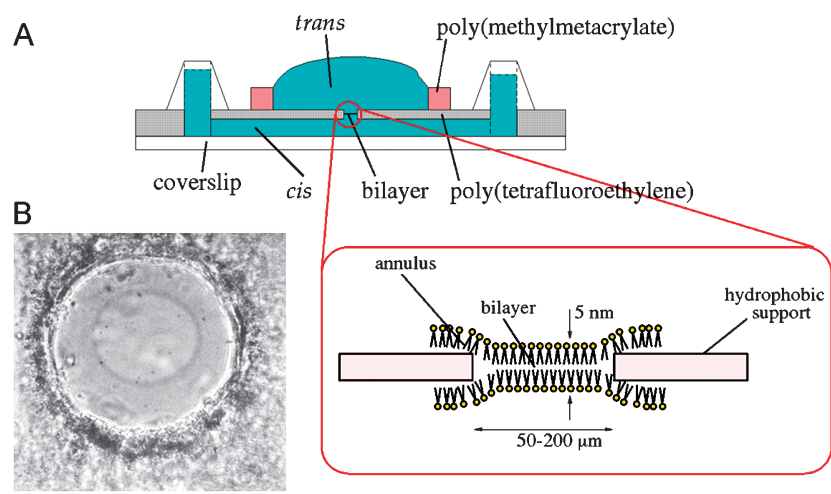

Fig. 3 Schematic cross-section of microfluidic device $a$ Schematic cross-section of the microfluidic device used in this work, which comprised a hot-embossed poly(tetrafluoroethylene) microfluidic channel with a laser micromachined aperture (thickness $<120 \mu \mathrm{m}$ ) where the bilayer was formed. The microfluidic channel was bonded to a glass coverslip $(22 \times 40 \mathrm{~mm})$ and a poly(methylmethacrylate) reservoir with a height of $\sim 2 \mathrm{~mm}$ and a volume of $\sim 50 \mu \mathrm{l}$

$b$ Typical transmission microscope image of a bilayer in the aperture

Bilayers were made by painting the same lipid mixture (Section 2.4) over the poly(tetrafluoroethylene) (PTFE) aperture using a brush. Thinning of the decane-lipid film was observed within a few minutes, resulting in a stable lipid bilayer that could be used over several hours. The thinning
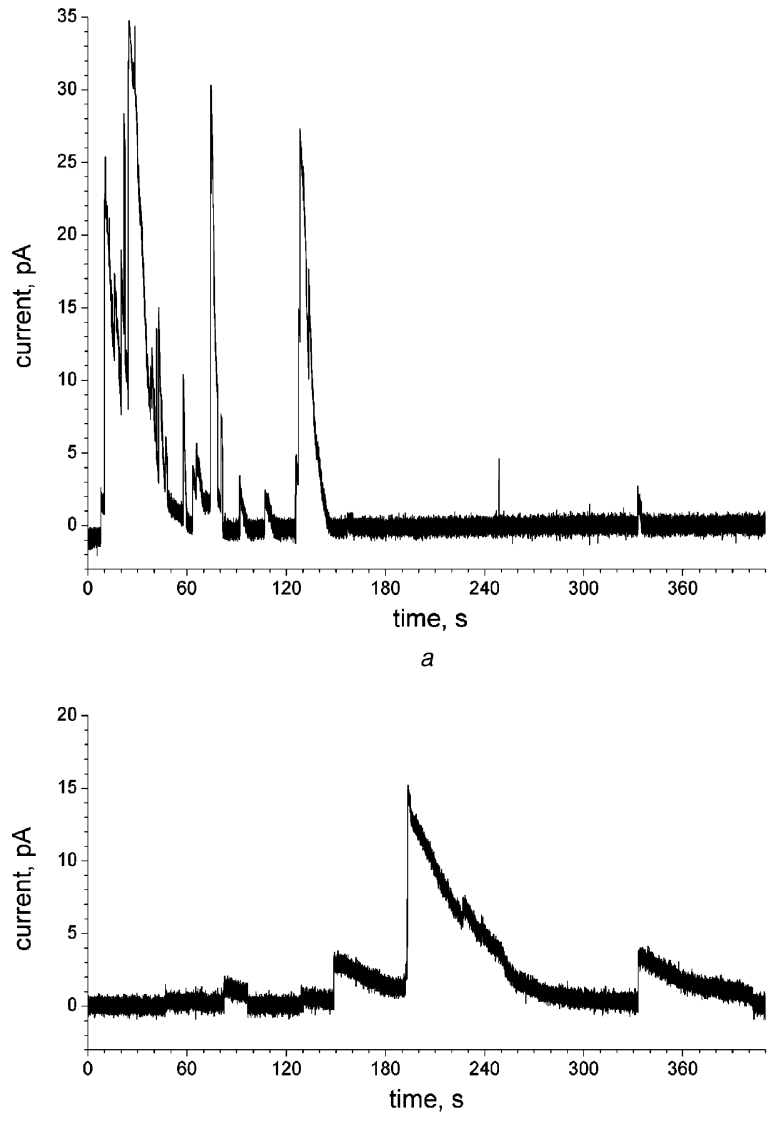

$c$ process was observed by transmission microscopy, as a lighter region was seen gradually to expand outwards as the bilayer formed, leaving a distinct annulus visible around the aperture (Fig. 3b). Simultaneously, the capacitance and conductance of the bilayer were monitored, using the same equipment as for the experiments reported above (Section 2.4). Final capacitance values ranged from 30 to $45 \mathrm{pF}$, corresponding to bilayers with a specific capacitance of approximately $0.6 \mu \mathrm{F} \mathrm{cm}^{-2}$. Vesicles were made in the same way as described above (Section 2.3), with $10 \mathrm{~mol} \%$ ergosterol and $50 \mu \mathrm{g} \mathrm{ml}^{-1}$ nystatin (but with $7.5 \mu \mathrm{M}$ instead of $7.5 \mathrm{mM}$ total lipid), and the same salt gradient was created between the two chambers, with the quantities to be injected adjusted according to the cis reservoir volume, which is only $\sim 50 \mu$ l.

\section{Results and discussion}

\subsection{Nystatin concentration modulates vesicle fusion}

Figure 4 shows different electrical recordings of a planar bilayer consisting of a mixture of the phospholipids POPE and POPC. In the absence of incorporated ion channels, the bilayer had a high resistance, and, consequently, the applied voltage did not result in a significant current. Current spikes were observed when unilamellar phospholipid-ergosterol vesicles, incubated with nystatin, were added to the aqueous solution on one side of the planar bilayer. Each current
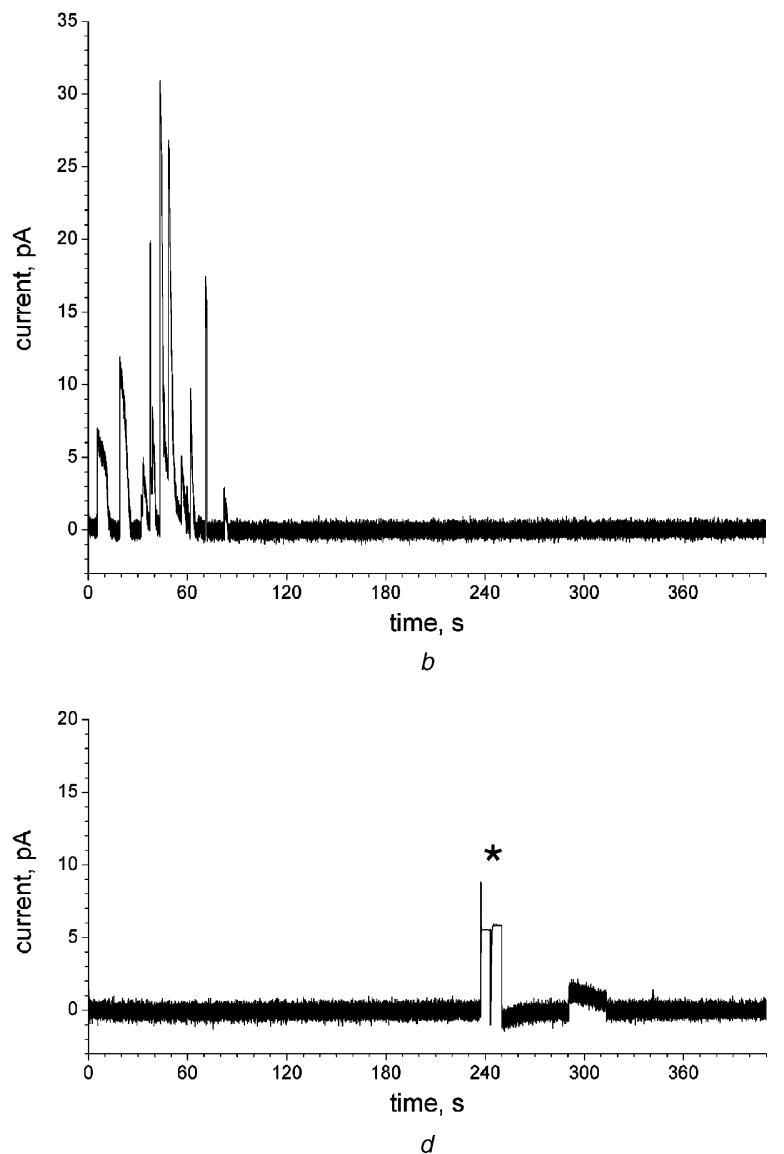

Fig. 4 Influence of nystatin concentration on vesicle fusion

Current traces of a planar bilayer of POPE/POPC (7:3 molar ratio) voltage clamped at $+100 \mathrm{mV}$. Recordings were started immediately after injection of $20 \mu \mathrm{l}$ of vesicle suspension and mixing by raising and lowering of the buffer in the cis compartment. Vesicles are composed of POPE/ POPC/POPS/ergosterol $=4: 2: 2: 2$ (molar ratio) and are incubated with various concentrations of nystatin: $60 \mu \mathrm{g} \mathrm{ml}{ }^{-1}$

a $50 \mu \mathrm{g} \mathrm{ml}^{-1}$

$b 40 \mu \mathrm{g} \mathrm{ml}^{-1}$

$c 30 \mu \mathrm{g} \mathrm{ml} \mathrm{l}^{-1}$

$d 30 \mu \mathrm{g} \mathrm{ml}^{-1}$

The asterisk denotes an interruption of the recording to raise and lower the buffer, a procedure which usually results in a new cycle of vesicle fusion 
spike represents the introduction of nystatin-ergosterol channels into the planar bilayer by a single vesicle fusion event. The abrupt increase in bilayer conductance reflects the short time scale of vesicle fusion, whereas the following gradual current decrease is caused by the diffusion-driven dissociation of the nystatin-ergosterol channels in the ergosterol-free planar bilayer. The amplitude of the current spikes and the time required for their decay depends on the concentration of nystatin and ergosterol, and typical working conditions are a nystatin concentration of $50-60 \mu \mathrm{g} \mathrm{ml}^{-1}$, a vesicle ergosterol content of $20-30 \mathrm{~mol} \%$ and a total lipid (phospholipid and sterol) concentration of 7.0-7.5 mM [27, 28, 48, 49].

In this study, we investigated the effect of varying the nystatin and ergosterol concentration on several parameters that are relevant for vesicle fusion and protein delivery to planar bilayers. The recording shown in Fig. $4 a$ was obtained with vesicles of POPE/POPC/POPS containing $20 \mathrm{~mol} \%$ ergosterol, which were incubated with $60 \mu \mathrm{g} \mathrm{ml}^{-1}$ of nystatin. After injection of the vesicle suspension into the cis compartment and mixing by raising and lowering of the solution in the compartment, a large number of vesicles (about 15) fuse within the first minute. Subsequently, the fusion rate slows down, and, 2 min after injection, fusion has stopped, except for an isolated event near the end of the recording. The amplitude of the current spikes varies considerably, with values ranging from 3 to $35 \mathrm{pA}$, most likely reflecting non ideal mixing of the nystatin stock solution and the vesicle suspension. Complete decay of the current spikes takes $\sim 10 \mathrm{~s}$ for the events with lower amplitude and $\sim 25 \mathrm{~s}$ for the most intense spikes, and, consequently, most fusion markers overlap. When the same experiment was carried out with $50 \mu \mathrm{g} \mathrm{ml}^{-1}$ nystatin (Fig. $4 b$ ), fusion only occurred within the first $1.5 \mathrm{~min}$ after vesicle injection, the average spike amplitude was about $30 \%$ lower, the current decay time was shorter (5-10 s), and consequently the fusion markers show considerably less overlap. A very different picture emerges when the nystatin concentration is lowered further to $40 \mu \mathrm{g} \mathrm{ml}^{-1}$, as seen in Fig. $4 c$, where only a small number of fusion events were recorded, and most of these were later than 2 min after injection. The current spikes do not exceed $15 \mathrm{pA}$, and complete current decay takes about $60 \mathrm{~s}$. At a nystatin concentration of $30 \mu \mathrm{g} \mathrm{ml}^{-1}$, no fusion events were observed until the solution in the compartment had been raised and lowered again. This procedure usually generates a fresh burst of vesicle fusion, but for this sample only an isolated low-amplitude fusion event occurred (Fig. 4d).

It appears that controlled fusion of vesicles is only attainable within a surprisingly narrow nystatin concentration range: $60 \mu \mathrm{g} \mathrm{ml}^{-1}$ results in too much fusion, and, with $40 \mu \mathrm{g} \mathrm{ml}^{-1}$, most fusion events are characterised by an unfavourable low-amplitude current spike and a slow current decay. This implies that vesicle fusion will not be observed when the nystatin is not properly solubilised (see Section 2.2). The abrupt change in fusion characteristics below $50 \mu \mathrm{g} \mathrm{ml}^{-1}$ nystatin can be explained by a recent fluorescence lifetime study on the interaction of nystatin with ergosterol-containing POPC vesicles [39]. Coutinho et al. could distinguish nystatin molecules that are bound to the vesicle surface from molecules that have actually penetrated into the bilayer core. The latter, channel-forming population abruptly arises when $\sim 50 \mu \mathrm{g} \mathrm{ml}^{-1}$ nystatin is present (extrapolated value for a $7.5 \mathrm{mM}$ total lipid vesicle suspension), whereas, at lower concentrations, all the nystatin molecules remain surface-associated. At this threshold amount of nystatin, an estimated $1 \%$ of the vesicle surface is covered with nystatin molecules [39].
Surface-associated nystatin molecules will be partly inserted into the lipid headgroup region, and, although this arrangement is sufficiently perturbing for lipid packing to result in channel-like activity [50], vesicle fusion will not give rise to the current spikes that are characteristic of dissociating nystatin-ergosterol channels (Figs. $4 a$ and $b$ ).

\subsection{Composition of unilamellar vesicles}

For a concentration of $50 \mu \mathrm{g} \mathrm{ml}^{-1}$ nystatin, the effect of different ergosterol molar ratios in the vesicles was investigated. Figure $5 b$ shows the first $3 \mathrm{~min}$ after vesicle injection of a current trace recorded for vesicles with $20 \mathrm{~mol} \%$ ergosterol. Although this is the same composition as used to obtain the trace in Fig. $4 b$, the number and shape of the fusion-induced current spikes also display features of the trace in Fig. $4 a$, indicating a slight variation in the (effective) nystatin concentration for this separate set of samples. When the ergosterol content is increased to $25 \%$ (Fig. 5a), the current spikes have a significantly longer decay time $(>60 \mathrm{~s})$, reflecting the longer time required for the larger amount of incorporated ergosterol to diffuse away into the planar bilayer. Lowering the ergosterol content instead to $15 \%$ reduces the current decay time to $\sim 10$ s for the spikes with 15-20 pA amplitude and to $\sim 20$ s for the low-intensity events, and most of the current spikes are almost separated from each other, although there is virtually no time interval between fusion events (Fig. $5 c$ ). However, when only $10 \%$ of the vesicle composition is ergosterol, the number of fusion events decreases, as does the current decay time, which is now $<10$ s for a current spike of $35 \mathrm{pA}$ and $\sim 5 \mathrm{~s}$ for an event with an intensity of $10 \mathrm{pA}$ (Fig. $5 d$ ). With 5\% ergosterol in the vesicles, fusion could not be observed.

This combination of a low vesicle fusion rate with easily observable and rapidly decaying current spikes led us to use $10 \%$ ergosterol and $50 \mu \mathrm{g} \mathrm{ml}^{-1}$ nystatin for all subsequent measurements. The number of fusing vesicles can be further reduced by injection of less than the $20 \mu \mathrm{l}$ of vesicle suspension used in these experiments (see below), or by using a more dilute vesicle suspension. We also evaluated the effect of the POPS component on fusion, initially introduced to mimic the composition of synaptic vesicles [27]. The absence of this negatively charged lipid did not influence vesicle fusion (data not shown) and reduces the number of 'foreign' molecules that are introduced into the planar bilayer of POPE and POPC. The presence of the curvature-preferring [51] lipid POPE in the vesicles is essential for fusion, but an occasional fusion event is observed when the planar bilayer is composed exclusively of POPC, in agreement with previous work [26]. Although we used unilamellar vesicles with a diameter of $400 \mathrm{~nm}$, vesicle fusion was also successful with vesicles with a diameter of $100 \mathrm{~nm}$ (data not shown). This is the lower limit of the vesicle size range of $100-1000 \mathrm{~nm}$ previously recommended for the nystatin-fusion method [28].

\subsection{Example of ion-channel delivery by vesicle fusion}

To demonstrate incorporation of a membrane peptide into a planar bilayer by nystatin-ergosterol modulated vesicle fusion, vesicles were prepared containing $A \beta(1-40)$, the shorter of the two beta-amyloid peptides that are abundant in the fibrillar plaques associated with Alzheimer's disease [41]. In its unstructured monomeric form, the $A \beta$ peptide can bind to charged membrane surfaces but not to the net uncharged surface of a POPE/POPC bilayer [52]. However, $\mathrm{A} \beta$ has a high tendency in aqueous solution to form $\beta$ structured oligomers and ill-defined aggregates, which cause 


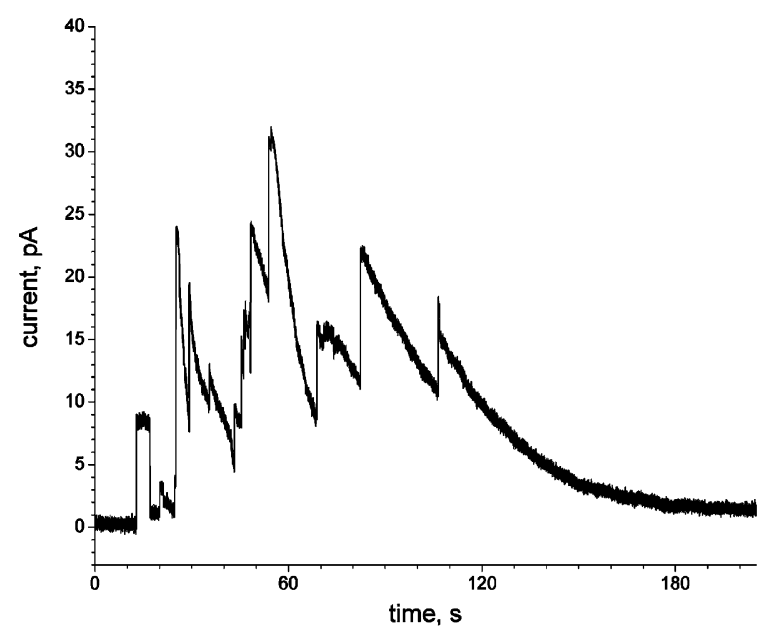

a

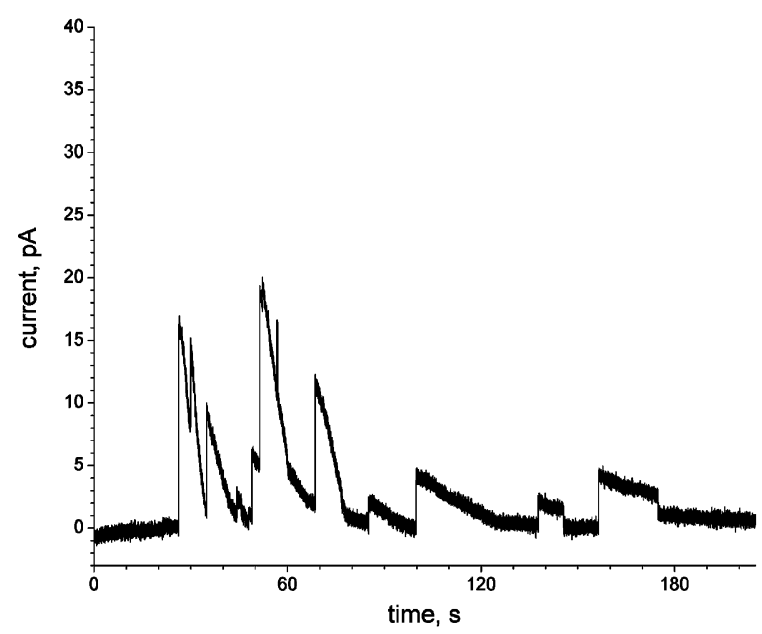

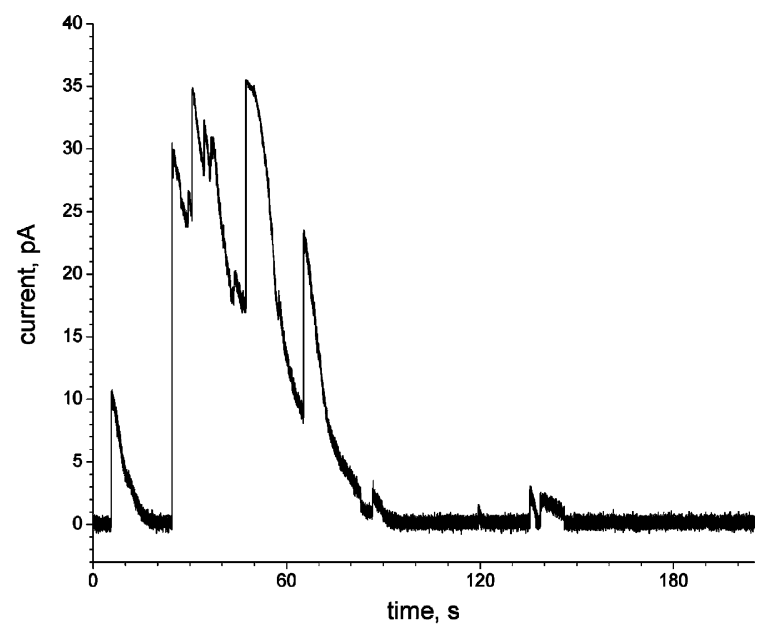

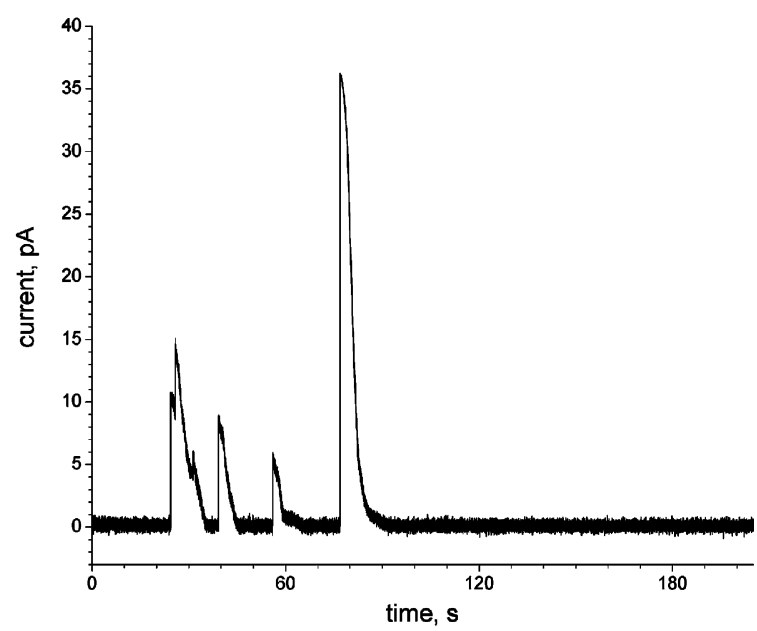

Fig. 5 Influence of ergosterol concentration on vesicle fusion

Current traces of a planar bilayer of POPE/POPC (7:3 molar ratio) voltage clamped at $+100 \mathrm{mV}$. Recordings were started immediately after injection of $20 \mu \mathrm{l}$ of vesicle suspension and mixing by raising and lowering of the buffer in the cis compartment. Vesicles are incubated with $50 \mu \mathrm{g} \mathrm{ml}^{-1}$ nystatin and are composed of POPE/POPC/POPS $=4: 2: 2$ (molar ratio) and various molar percentages of ergosterol a $25 \%$

b $20 \%$

c $15 \%$

$d 10 \%$

a large increase in conductance in planar bilayer experiments [53, 54]. Premixing peptide and lipids in organic solvent (see Section 2) should result in stable association of $\mathrm{A} \beta$ with the vesicles, and, as non-vesicular $\mathrm{A} \beta$ cannot bind to the planar bilayer in its monomeric form and would induce large currents $(>100 \mathrm{pA}$ under our experimental conditions [53]) in its oligomeric form, incorporation of $\mathrm{A} \beta$ by vesicle fusion ought to be easily recognised.

As shown in Fig. 6, injection of a suspension of vesicles containing $0.5 \mathrm{~mol} \%$ of $\mathrm{A} \beta$ results in controlled incorporation of the peptide into the planar bilayer. The first clear vesicle fusion event causes irregular, low-intensity current 'activity', and the second clear fusion event results in continuous channel-like activity of $A \beta$, which can be studied after the nystatin-ergosterol channels have dissociated (see inset). It should be noted that the current decay of the nystatin-ergosterol channels takes longer than for peptide-free vesicles with the same lipid composition, suggesting that the presence of the peptides influences the diffusion rate of ergosterol. Because the onset of $A \beta$ activity coincides with vesicle fusion, and excessive conductances are not observed, it can be concluded that the $\mathrm{A} \beta$ peptides are delivered to the planar bilayer by vesicle fusion and have not incorporated from the aqueous phase. The expanded trace (Fig. 6, inset) reveals that the $\mathrm{A} \beta$ activity is similar to the channel-like 'spiky fast' behaviour of $A \beta$, as seen when small amounts of monomeric peptide are added to a charged bilayer from aqueous solution [55], illustrating the potential of vesicle fusion to introduce controlled amounts of protein or peptide in a planar bilayer.

\subsection{Vesicle fusion on chip}

The nystatin-ergosterol vesicle fusion method was also investigated for a planar bilayer on a chip. Only stable bilayers with an electrical leakage current of below $0.1 \mathrm{pA}$ (at an applied potential of $+65 \mathrm{mV}$ ) were used. The stability of these bilayers was comparable with that of the bilayers in the conventional bilayer apparatus; planar bilayers that exhibited a constant capacitance and a minimum leakage for several hours could readily be obtained with both systems, although there are variations between individual experiments. Vesicle fusion in the microdevice was initiated by introducing a small volume of vesicle suspension $\left(7.5 \mu \mathrm{M}\right.$ total lipid; $10^{9}$ vesicles $\left.\mathrm{ml}^{-1}\right)$ into the upper chamber of the horizontal bilayer using a pipette. Vesicles slowly diffused through the suspending 


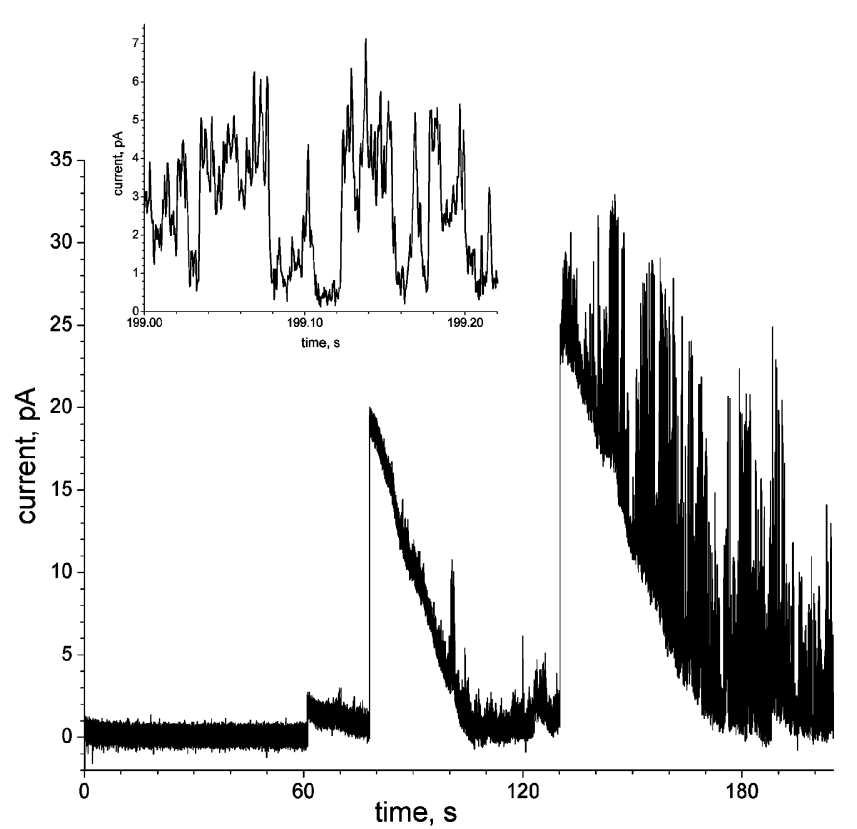

Fig. 6 Controlled delivery of $A \beta(1-40)$ to a lipid bilayer by vesicle fusion

Current trace of a planar bilayer of POPE/POPC (7:3 molar ratio) voltage clamped at $+100 \mathrm{mV}$. Recordings were started immediately after injection of $10 \mu \mathrm{l}$ of vesicle suspension and mixing by raising and lowering of the buffer in the cis compartment. Vesicles are composed of POPE/POPC/ergosterol $=6: 3: 1$ (molar ratio) and are incubated with $50 \mu \mathrm{g} \mathrm{ml}^{-1}$ of nystatin. The molar ratio of $\mathrm{A} \beta(1-40)$ to total lipid in the vesicles is 1:200. The inset presents an expanded view of the end of the recording, when the nystatinergosterol channels have dissociated and only the conductance resulting from the introduced $A \beta(1-40)$ peptide remains

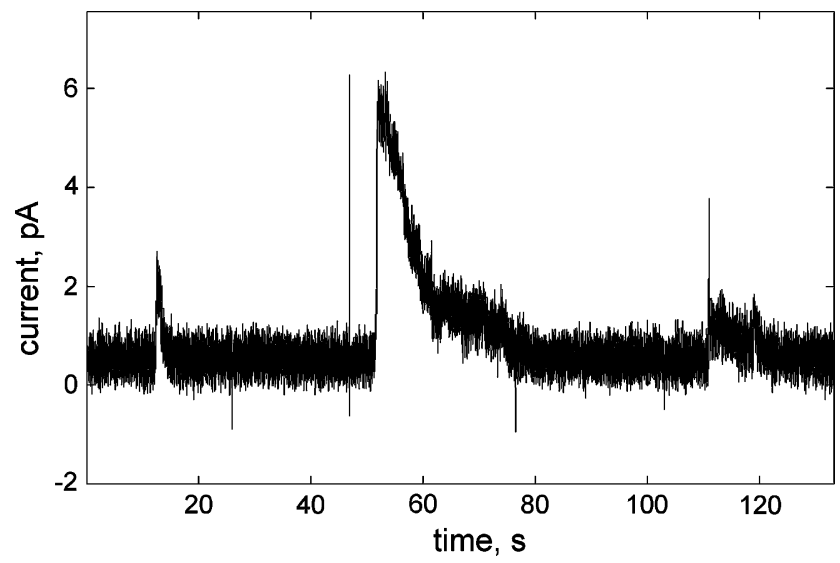

Fig. 7 Electrical recording on chip

Current trace of a planar bilayer of POPE/POPC (7:3 molar ratio) voltage clamped at $+65 \mathrm{mV}$. The planar bilayer is formed on a chip and the trace is recorded after injection of $4 \mu \mathrm{l}$ of diluted vesicle suspension $(7.5 \mu \mathrm{M}$ total lipid) to the upper chamber. Vesicles are composed of POPE/POPC/ergosterol $=6: 3: 1$ (molar ratio) and are incubated with $50 \mu \mathrm{g} \mathrm{ml}^{-1}$ of nystatin. Three fusion events are visible

buffer and occassionally landed on the bilayer surface. If no fusion was observed within the first few minutes, the buffer solution was gently agitated with a pipette, which normally resulted in vesicles fusing with the bilayer. As with the conventional system, vesicle fusion does not alter the stability or the capacitance of the bilayer, as long as the number of fusing vesicles is not excessive. A typical vesicle fusion trace obtained with the chip is shown in
Fig. 7, where three separate fusion events are detected, each showing the 'classical' decay of current with time, as the nystatin-ergosterol channels dissociate in the large planar bilayer. Also in this respect, the behaviour of the microdevice was similar to the conventional bilayer apparatus (Fig. 5d).

\subsection{Molecular mechanism of nystatin- ergosterol current decay}

Because the composite channels of the polyene antibiotics and ergosterol have not been characterised at the singlechannel level, the conductance of a single nystatin-ergosterol channel is not known, and therefore it is a matter of debate how many nystatin-ergosterol channels contribute to the current spike associated with vesicle fusion. Based on the very low conductance $(\sim 2 \mathrm{pS})$ reported for single channels of nystatin-cholesterol [56, 57], and on the large number of nystatin molecules available for each vesicle ( $\sim 1000$ for vesicles of $100 \mathrm{~nm}$ ), it has been suggested that hundreds of low-conductance nystatin-ergosterol channels contribute to the current spike [27]. However, the recent fluorescence lifetime study discussed above [39] demonstrates that a large number of nystatin molecules at the vesicle surface is required before nystatin penetrates the vesicular membrane, suggesting that only a fraction of the nystatin molecules actually participate in channel formation. Moreover, at a nystatin-lipid ratio close to our experimental conditions, analysis of the kinetics of $\mathrm{K}^{+}$ efflux from the vesicles indicates that, on average, there are only $\sim 1.5$ pores per vesicle present [39].

Significantly, after a substantial amount of vesicle fusion under the conditions described for Fig. $4 b$, we observed single channel behaviour in the absence of membrane proteins or peptides. The current trace in Fig. $8 a$ shows continuous single-channel activity and two vesicle fusion events. This can be interpreted as a single nystatinergosterol channel that does not dissociate because it is present in a stable, ergosterol-rich domain [58] of the planar bilayer, created by substantial amounts of vesicle fusion. The two vesicles that fuse at 11 and $16 \mathrm{~s}$ in this trace are marked by a normal gradual current decay, corresponding to dissociation of the incorporated nystatin-ergosterol channels in an ergosterol-poor region of the planar bilayer. The observation that the initial current of the vesicle fusion spikes $(\sim 12 \mathrm{pA})$ is very similar to the amplitude of the single nystatin-ergosterol channel, strongly suggests that the vesicles only deliver one nystatin-ergosterol channel to the planar bilayer.

A histogram of the distribution of channel openings and closings (Fig. 8b) shows that the single channel is most often in a low-conductance state $(\sim 10-50 \mathrm{pS}$ under the conditions described in the Caption) and frequently in a highconductance state $(\sim 170 \mathrm{pS})$, whereas it is very rarely closed. Complete closure of the channel is visible at 0.2, 2.4 and $6.8 \mathrm{~s}$ in the expanded trace (Fig. $8 c$ ), which also shows typical lifetimes of the two conductance states at the applied potential of $+100 \mathrm{mV}$. At lower, and especially at negative potential, the frequency of occurrence and the lifetime of the high-conductance state were greatly reduced, and the low-conductance state was increasingly favoured. From -50 to $+50 \mathrm{mV}$, the current-voltage relationship [59] of the single nystatin-ergosterol channel (Fig. $8 d$ ) is characterised by a slope conductance of $49 \pm 2 \mathrm{pS}$ and $265 \pm 2 \mathrm{pS}$ for the low-conductance and high-conductance states, respectively. The reversal potential for both states is $+16 \mathrm{mV}$, indicating that the channel is weakly anion selective, as previously observed for nystatin-cholesterol channels $[32,33]$. 

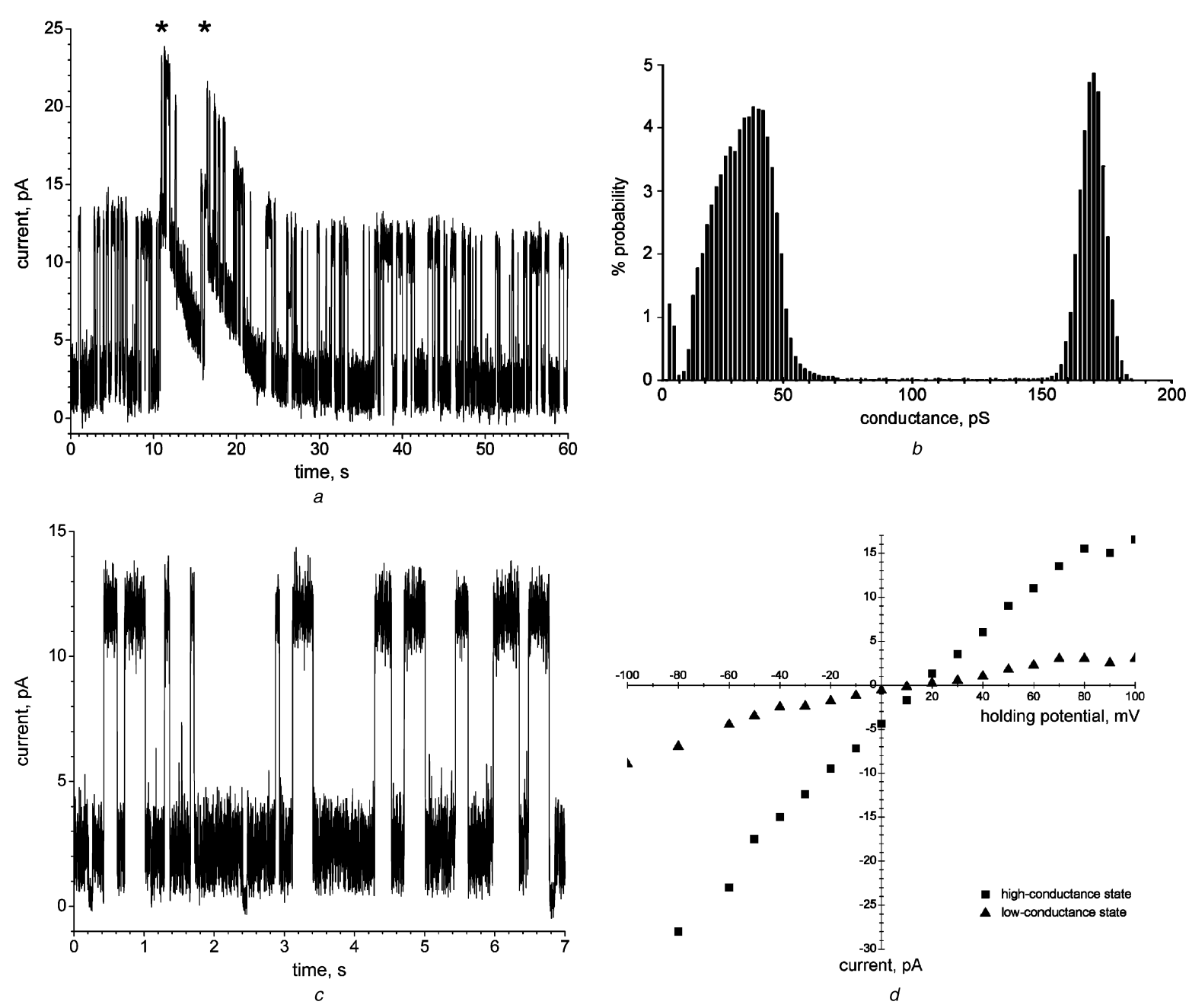

Fig. 8 Single nystatin-ergosterol channel activity

$a$ Snapshot of single nystatin-ergosterol channel activity after a substantial amount of vesicle fusion (vesicle composition: molar ratio POPE/POPC/ POPS/ergosterol $=4: 2: 2: 2,50 \mu \mathrm{g} \mathrm{ml}^{-1}$ nystatin) into a planar bilayer of POPE/POPC (7:3). The current trace, recorded at $+100 \mathrm{mV}$ in the presence of an osmotic gradient (cis/trans $=720 / 150 \mathrm{mM} \mathrm{NaCl}$ ), also shows two vesicle fusion events (denoted by asterisks)

$b$ Histogram showing the distribution of conductances after neutralisation of the osmotic gradient (cis/trans $=720 / 720 \mathrm{mM} \mathrm{NaCl},+100 \mathrm{mV}$ holding potential)

$c$ Expanded view of a current trace recorded at $+100 \mathrm{mV}$ holding potential in the absence of an osmotic gradient ( cis $/$ trans $=720 / 720 \mathrm{mM} \mathrm{NaCl}$ ); the high-conductance, low-conductance and closed state of the single channel can clearly be distinguished

$d$ Current-voltage relationship of the low-conductance and the high-conductance states in symmetrical conditions of $\mathrm{NaCl}($ cis $/$ trans $=720 / 720 \mathrm{mM})$

This channel could also be observed immediately after vesicle fusion (vesicle composition as in Fig. 7) into planar bilayers of POPC which contain $3.5 \pm 1 \mathrm{~mol} \%$ ergosterol. Lower ergosterol concentrations resulted in a standard (although elongated) decaying current spike, whereas higher concentrations gave rise to a constant current that corresponds to the channel high-conductance state (data not shown). Apparently, in a bilayer with only $\sim 3.5 \%$ ergosterol, nystatin-ergosterol channels introduced by vesicle fusion cannot dissociate but are sufficiently destabilised to enable (partial) channel closing and reopening. Based on the preliminary characterisation of a single nystatin-ergosterol channel presented here, we propose that vesicle fusion typically leads to the incorporation of only one or two nystatin-ergosterol channels into the planar bilayer, and that the gradual decay of the current spike represents the gradual inactivation of this small number of channels.

In this scenario, the shape of the current spike will be influenced by the location of the channels in the patch of phospholipids and ergosterol inserted into the planar bilayer by vesicle fusion. Compared with channels near the centre of this patch, channels near the edge will dissociate more rapidly through diffusion of their ergosterol components, because they are in closer proximity to the ergosterol-free part of the planar bilayer. In general, the mechanism of nystatin-ergosterol channel formation and dissociation illustrates the necessity of combined optical and electrical recordings to understand the assembly, function and regulation of (multimeric) ion channel proteins.

\section{Conclusions}

With correct handling of the nystatin component, the nystatin-ergosterol vesicle fusion technique is a promising method for the controlled incorporation of membrane peptides and proteins into artificial lipid bilayers. We have shown delivery of a small amount of the $A \beta(1-40)$ peptide to a conventional planar bilayer and have demonstrated vesicle fusion with a bilayer in a microfabricated device. Particularly in combination with microfluidics technology, the time between vesicle fusion events is sufficiently long to neutralise the salt gradient and thus to prevent additional protein incorporation by vesicle fusion. The potential of the nystatinergosterol vesicle fusion method to deliver purified ion 
channel proteins to conventional planar bilayers has already been demonstrated [60], and our future efforts will focus on the incorporation of a fluorescently labelled multimeric membrane protein into a bilayer on a chip. Such devices will have widespread potential applications, for instance in the fields of single-molecule biophysics, drug-screening technologies and in the development of high-sensitivity biosensors.

\section{Acknowledgments}

The authors would like to thank Dr Dirk Rijkers (Utrecht University) for providing the $\mathrm{A} \beta(1-40)$ peptide and Professor R.W. Eason (ORC, Southampton University) for access to the femtosecond laser micromachining tool.

BBSRC, EPSRC, MRC and MoD provided funding through the Bionanotechnology IRC. M.R.R. de Planque was funded by EMBO.

\section{References}

1 International Human Genone Sequencing Consortium 'Initial sequencing and analysis of the human genome', Nature, 2001, 409 pp. $860-921$

2 Wallin, E., and von Heijne, G.: 'Genome-wide analysis of integral membrane proteins from eubacterial, archaean, and eukaryotic organisms', Protein Sci., 1998, 7, pp. 1029-1038

3 Drews, J.: 'Strategic trends in drug discovery', Science, 2000, 287, pp. $1960-1964$

4 Hopkins, A.L., and Groom, C.R.: 'The druggable genome', Nat. Rev. Drug Discov., 2003, 1, pp. 727-730

5 Tusnády, G.E., Dosztányi, Z., and Simon, I.: 'Transmembrane proteins in the Protein Data Bank: identification and classification', Bioinformatics, 2004, 20, pp. 2964-2972

6 Gennis, R.B.: 'Biomembranes: Molecular Structure and Function' (Springer, New York, 1989)

7 Neher, E., and Sakmann, B.: 'Single-channel currents recorded from membrane of denervated frog muscle fibres', Nature, 1976, 260, pp. 799-802

8 Miller, C., and Racker, E.: ' $\mathrm{Ca}{ }^{++}$-induced fusion of fragmented sarcoplasmic reticulum with artificial planar bilayers', J. Membr. Biol., 1976, 9, pp. 283-300

9 Schütz, G.J., Sonnleitner, M., Hinterdorfer, P., and Schindler, H. 'Single molecule microscopy of biomembranes', Mol. Membr. Biol. 2000, 17, pp. 17-29

10 Ishijima, A., and Yanagida, T.: 'Single molecule nanobioscience', Trends Biochem. Sci., 2001, 26, pp. 438-444

11 MacDonald, A.G., and Wraight, P.C.: 'Combined spectroscopic and electrical recording techniques in membrane research: prospects for single channel studies', Prog. Biophys. Molec. Biol., 1995, 63, pp. 1-29

12 Duclohier, H., Helluin, O., Lea, E., Mackie, A.R., and Ladha, S.: 'Coupling optical and electrical measurements in artificial membranes: lateral diffusion of lipids and channel forming peptides in planar bilayers', Biol. Proced. Online, 1998, 1, pp. 81-91

13 Borisenko, V., Lougheed, T., Hesse, J., Füreder-Kitzmüller, E., Fertig, N., Behrends, J.C., Woolley, G.A., and Schütz, G.J.: 'Simultaneous optical and electrical recording of single gramicidin channels', Biophys. $J ., 2003,84$, pp. 612-622

14 Harms, G.S., Orr, G., Montal, M. Thrall, B.D., Colson, S.D., and Lu, H.P.: 'Probing conformational changes of gramicidin ion channels by single-molecule patch-clamp fluorescence microscopy', Biophys. J., 2003, 85, pp. $1826-1838$

15 Ide, T., Takeuchi, Y., Aoki, T., and Yanagida, T.: 'Simultaneous optical and electrical recording of a single ion-channel', Jpn. J. Physiol., 2002, 52, pp. 429-434

16 Pantoja, R., Sigg, D., Blunck, R., Bezanilla, F., and Heath, J.R.: 'Bilayer reconstitution of voltage-dependent ion channel using a microfabricated silicon chip', Biophys. J., 2001, 81, pp. 2389-2394

17 Trojanowicz, M., and Mulchandani, A.: 'Analytical applications of planar bilayer lipid membranes', Anal. Bioanal. Chem., 2004, 379, pp. $347-350$

18 Peterman, M.C., Ziebarth, J.M., Braha, O., Bayley, H., Fishman, H.A., and Bloom, D.M.: 'Ion channels and lipid bilayer membranes under high potentials using microfabricated apertures", Biomed. Microdevices, 2002, 4, pp. 231-236

19 Ide, T., and Yanagida, T.: 'An artificial lipid bilayer formed on an agarose-coated glass for simultaneous electrical and optical mesurement of single ion channels', Biochem. Biophys. Res. Commun., 1999, 265, pp. 595-599

20 Morgan, H.: 'Artificial lipid bilayers in a microfabricated system'. Proc. $\mu$ TAS 2004, 2004, Vol. 1, pp. 330-332

21 Sandison, M.E., and Morgan, H.: 'Rapid fabrication of polymer microfluidic systems for the production of artificial bilayers', J. Micromech. Microeng., 2005, 15, pp. S139-S144
22 Mirzabekov, T.A., Silberstein, A.Y., and Kagan, B.L.: 'Use of planar lipid bilayer membranes for rapid screening of membrane active compounds', Methods Enzymol., 1999, 294, pp. 661-674

23 Cornell, B.A., Braach-Maksvytis, V.L., King, L.G., Osman, P.D. Raguse, B., Wieczorek, L., and Pace, R.J.: 'A biosensor that uses ionchannel switches', Nature, 1997, 387, pp. 580-583

24 Seddon, A.M., Curnow, P., and Booth, P.J.: 'Membrane proteins, lipids and detergents: not just a soap opera', Biochim. Biophys. Acta, 2004, 1666, pp. 105-117

25 Cohen, F.S., Akabas, M.H., and Finkelstein, A.: 'Osmotic swelling of phospholipid vesicles causes them to fuse with a planar phospholipid bilayer membrane', Science, 1982, 217, pp. 458-460

26 Cohen, F.S., Akabas, M.H., Zimmerberg, J., and Finkelstein, A.: 'Parameters affecting the fusion of unilamellar phospholipid vesicles with planar bilayer membranes', J. Cell Biol., 1984, 98 pp. $1054-1062$

27 Woodbury, D.J., and Miller, C.: 'Nystatin-induced liposome fusion', Biophys. J., 1990, 58, pp. 833-839

28 Woodbury, D.J.: 'Nystatin/ergosterol method for reconstituting ion channels into planar lipid bilayers', Methods Enzymol., 1999, 294, pp. 319-339

29 Bruheim, P., Borgos, S.E.F., Tsan, P., Sletta, H., Ellingsen, T.E. Lancelin, J.M., and Zotchev, S.B.: 'Chemical diversity of polyene macrolides produced by Streptomyces noursei ATCC 11455 and recombinant strain ERD44 with genetically altered polyketide synthase NysC', Antimicrob. Agents Chemother., 2004, 48, pp. $4120-4129$

30 Omura, S. (Ed).: 'Macrolide antibiotics: chemistry, biology, and practice' (Academic Press, New York, 2002, 2nd edn.)

31 Baginski, M., Resat, H., and Borowski, E.: 'Comparative molecular dynamics simulations of amphotericin B-cholesterol/ergosterol membrane channels', Biochim. Biophys. Acta, 2002, 1567, pp. $63-78$

32 Cass, A., Finkelstein, A., and Krespi, V.: 'The ion permeability induced in thin lipid membranes by the polyene antibiotics nystatin and amphotericin B', J. Gen. Physiol., 1970, 56, pp. 100-124

33 Andreoli, T.E., and Monahan, M.: 'The interaction of polyene antibiotics with thin lipid membranes', J. Gen. Physiol., 1968, 52, pp. $300-325$

34 de Kruijff, B. Gerritsen, W.J, Oerlemans, A, Demel, R.A. and van Deenen, L.L.M.: 'Polyene antibiotic-sterol interactions in membranes of Acholeplasma laidlawii cells and lecithin liposomes. I. Specificity of the membrane permeability changes induced by the polyene antibiotics', Biochim. Biophys. Acta, 1974, 339, pp. $30-43$

35 de Kruijff, B., and Demel, R.A.: 'Polyene antibiotic-sterol interactions in membranes of Acholeplasma laidlawii cells and lecithin liposomes. III. Molecular structure of the polyene antibiotic-cholesterol complex', Biochim. Biophys. Acta, 1974, 339, pp. 57-70

36 Kleinberg, M.E., and Finkelstein, A.: 'Single-length and double-length channels formed by nystatin in lipid bilayer membranes', J. Membr. Biol., 1984, 80, pp. 257-269

37 Vertut-Croquin, A., Bolard, J., Chabbert, M., and Gary-Bobo, C.: 'Differences in the interaction of the polyene antibiotic amphotericin B with cholesterol- or ergosterol-containing phospholipid vesicles. A circular dichroism and permeability study', Biochemistry, 1983, 22, pp. 2939-2944

38 Bolard, J., Legrand, P., Heitz, F., and Cybulska, B.: 'One-sided action of amphotericin B on cholesterol-containing membranes is determined by its self-association in the medium', Biochemistry, 1991, 30, pp. $5707-5715$

39 Coutinho, A., Silva, L., Fedorov, A., and Prieto, M.: 'Cholesterol and ergosterol influence nystatin surface aggregation: relation to pore formation', Biophys. J., 2004, 87, pp. 3264-3276

40 Matsumori, N., Sawada, Y., and Murata, M.: 'Mycosamine orientation of amphotericin B controlling interaction with ergosterol: sterol-dependent activity of conformation-restricted derivatives with an amino-carbonyl bridge', $J$. Am. Chem. Soc., 2005, 127, pp. $10667-10675$

41 Morgan, C., Colombres, M., Nuñez, M.T., and Inestrosa, N.C. 'Structure and function of amyloid in Alzheimer's disease', Prog. Neurobiol., 2004, 74, pp. 323-349

42 Budavari, S., O'Neil, M.J., Smith, A., and Heckelman, P.E.: 'The Merck Index, an encyclopedia of chemicals, drugs, and biologicals' (Merck \& Co., Rahway, New Jersey, 1989, 11th edn.), entry number 6658

43 Worthen, D.R., Jay, M., and Bummer, P.M.: 'Methods for the recovery and purification of polyene antifungals', Drug. Dev. Ind. Pharm., 2001, 27, pp. 277-286

44 Jao, S., Ma, K., Talafous, J., Orlando, R., and Zagorski, M.G.: 'Trifluoroacetic acid pretreatment reproducibly disaggregates the amyloid $\beta$-peptide', Amyloid Int. J. Exp. Clin. Invest., 1997, 4, pp. $240-252$

45 Cohen, F.S., Niles, W.D., and Akabas, M.H.: 'Fusion of phospholipid vesicles with a planar membrane depends on the membrane permeability of the solute used to create the osmotic pressure', J. Gen. Physiol., 1989, 93, pp. 201-210

46 Niles, W.D., Cohen, F.S., and Finkelstein, A.: 'Hydrostatic pressures developed by osmotically swelling vesicles bound to planar membranes', J. Gen. Physiol., 1989, 93, pp. 211-244

47 Becker, H., and Gärtner, C.: 'Polymer microfabrication methods for microfluidic analytical applications', Electrophoresis, 2000, 21, pp. $12-26$ 
48 Anzai, K., Ogawa, K., Ozawa, T., and Yamamoto, H.: 'Quantitative comparison of two types of planar bilayers - folded and painted - with respect to fusion with vesicles', J. Biochem. Biophys. Methods, 2001, 48, pp. 283-291

49 Kelly, M.L., and Woodbury, D.J.: 'Ion channels from synaptic vesicle membrane fragments reconstituted into lipid bilayers', Biophys. J., 1996, 70, pp. 2593-2599

50 Shai, Y.: 'Mode of action of membrane active antimicrobial peptides', Biopolymers, 2002, 66, pp. 236-248

51 de Kruijff, B.: 'Biomembranes. Lipids beyond the bilayer', Nature, 1997, 386, pp. 129-130

52 McLaurin, J., and Chakrabartty, A.: 'Characterization of the interactions of Alzheimer $\beta$-amyloid peptides with phospholipid membranes', Eur. J. Biochem., 1997, 245, pp. 355-363

53 Kayed, R., Sokolov, Y., Edmonds, B., McIntire, T.M., Milton, S.C., Hall, J.E., and Glabe, C.G.: 'Permeabilization of lipid bilayers is common conformation-dependent activity of soluble amyloid oligomers in protein misfolding diseases', J. Biol. Chem., 2004, 279, pp. 46363-46366

54 Lin, H., Bhatia, R., and Lal, R.: 'Amyloid $\beta$ protein forms ion channels: implications for Alzheimer's disease pathophysiology', FASEB J., 2001, 15, pp. 2433-2444
55 Kourie, J.I., Henry, C.L., and Farrelly, P.: 'Diversity of amyloid $\beta$ protein fragment[1-40]-formed channels', Cell. Mol. Neurobiol., 2001, 21, pp. $255-284$

56 Ermishkin, L.N., Kasumov, K.M., and Potzeluyev, V.M.: 'Single ionic channels induced in lipid bilayers by polyene antibiotics amphotericin B and nystatine', Nature, 1976, 262, pp. 698-699

57 Kasumov, K.M., Borisova, M.P., Ermishkin, L.N., Potseluyev, V.M Silberstein, A.Y., and Vainshtein, V.A.: 'How do ionic channel properties depend on the structure of polyene antibiotics?', Biochim. Biophys. Acta, 1979, 551, pp. 229-237

58 Arora, R. Raghuraman, H., and Chattopadhyay, A.: 'Influence of cholesterol and ergosterol on membrane dynamics: a fluorescence approach', Biochem. Biophys. Res. Commun., 2004, 318, pp. $920-926$

59 Hille, B.: 'Ion Channels of Excitable Membranes' (Sinauer Associates, Sunderland, Massachusetts, 2001, 3rd edn. )

60 Bear, C.E., Li, C.H., Kartner, N., Bridges, R.J., Jensen, T.J., Ramjeesingh, M., and Riordan, J.R.: 'Purification and functional reconstitution of the cystic fibrosis transmembrane conductance regulator (CFTR)', Cell, 1992, 68, pp. $809-818$ 